PARCERIA PARA FORMULAÇÃO DE PARECER TÉCNICO: ESTUDO

TÉCNICO DA UFPR EM PROCESSO DE REINTEGRAÇÃO

DE POSSE DE FAIXA DE DOMÍNIO DE FERROVIA EM ALMIRANTE

TAMANDARÉ-PR, EM AÇÃO CIVIL PÚBLICA PROPOSTA PELA DPU

OPINION-MAKING PARTNERSHIP UFPR'S TECHINICAL STUDY IN THE PROCESS OF

REPOSSESSION OF RAILEOVE TRACK IN ALMIRANTE TAMANDARÉ - PR, IN A PUBLIC CIVIL ACTION PROPOSED BY DPU

\begin{abstract}
Daniele Regina Pontes ${ }^{1}$
Doutora em Direito danielepontes.ufpr@gmail.com

Anelise Schmitz

Mestre em Engenharia Civil - Infraestrutura e Gerência Viária

José Ricardo Vargas de Faria

Doutor em Planejamento Urbano. Engenheiro Civil

Gabriel Queiroz de Camargo

Advogado - Estudante de Pós-graduação em Planejamento Urbano

Larissa Pinho

Estudante de Engenharia Cartográfica e de Agrimensura

Priscila Borges Alves

Estudante de Engenharia Cartográfica e de Agrimensura
\end{abstract}

\title{
INTRODUÇÁO
}

A partir da necessidade de realizar um estudo técnico a respeito das ocupaçóes nas adjacências da ferrovia em Almirante Tamandaré-PR, nos autos de ação civil pública $\mathrm{n}^{\circ}$. 5042024-28.2018.4.04.7000, em trâmite na $1^{\text {a }}$ Vara Federal de Curitiba, proposta pela DPU contra o Departamento Nacional de Infraestrutura de Transportes (DNIT), Agência Nacional de Transportes Terrestres (ANTT), Estado do Paraná, Município de Almirante Tamandaré, União e Rumo Malha Sul S.A., surgiu a parceria com a Universidade Federal do Paraná, em específico com o Centro de Estudos em Planejamento e Políticas Urbanas - Setor de Tecnologia, composto por equipe multidisciplinar de engenheiros civis,

\footnotetext{
1 Equipe Técnica
} 
advogados, estudantes de cartografia, agrimensura, engenharia civil, arquitetura e outros, coordenados pelos seguintes professores orientadores: Daniele Regina Pontes (Doutora em Direito); José Ricardo Vargas de Faria (Engenheiro Civil - Doutor em Planejamento Urbano); e Anelise Schmitz (Mestre em Engenharia Civil - Infraestrutura e Gerência Viária). Cumpre destacar que a aludida equipe também contou com o auxílio das estagiárias Fernanda Barboza da Silva e Gabriela Langer, ambas do ofício da Defensoria Regional de Direitos Humanos e Tutela Coletiva no Estado do Paraná. De igual modo, importante ressaltar que a aludida ação civil pública foi proposta pela Defensora Pública Federal, Dra. Carolina Balbinott Bunhak, então Defensora Regional de Direitos Humanos e Tutela Coletiva no Estado do Paraná, e agora acompanhada pelo Dr. João Juliano Josué Francisco, atual Defensor Regional de Direitos Humanos e Tutela Coletiva no Estado do Paraná, que foi fundamental para a concretização da parceria entre DPU e UFPR.

O referido estudo teve por finalidade identificar as condições gerais de uso e ocupação das áreas atingidas pelos impactos e riscos decorrentes da ferrovia na área urbana; apresentar características relevantes de urbanização da faixa de ocupação e análise de documentos sobre a implantação da ferrovia e condicionantes locais; identificar os procedimentos realizados pela concessionárias nas áreas lindeiras a operação das atividades de transporte; analisar a multiplicidade de interesses sobrepostos sobre as faixas de segurança e de domínio, as responsabilidades e capacidades para possíveis soluçóes e encaminhamentos e, especialmente, indicar recomendaçóes técnicas que possam servir à mitigação dos impactos e riscos decorrentes do aproveitamento ou não das áreas contíguas à ferrovia.

Diante disso, o estudo elaborado por equipe com expertise e a devida chancela de conceituada Universidade Pública no estado do Paraná (UFPR), buscou propor soluçóes e medidas de forma a auxiliar a resolução de conflito habitacional, incluindo pedidos de mapeamento e diagnóstico dos locais afetados, bem como solicitação de realocação das famílias atingidas, após profundo diagnóstico e também a participação no processo de eventual remoção pelos entes públicos e empresa privada envolvida, com o escopo de proporcionar uma decisão justa e qualificada por parte do Poder Judiciário.

\section{Estudo Técnico}

No 01/2019

CEPPUR
Estudo técnico em processo de reintegração de posse de faixa de domínio de ferrovia em Almirante Tamandaré, PR.

REF.: Solicitação DPU.

\section{IDENTIFICAÇÃO DOS SOLICITANTES}

Defensoria Pública da União (DPU).

\section{FINALIDADE E OBJETO DO ESTUDO}


Os estudos técnicos apresentados neste Parecer tem por finalidade:

(i) identificar as condições gerais de uso e ocupação das áreas atingidas pelos impactos e riscos decorrentes da Ferrovia que atravessa a área urbana do Município de Almirante Tamandaré, Estado do Paraná;

(ii) apresentar características relevantes de urbanização da faixa de ocupação e analisar relatórios e documentos, o histórico de implantação da Ferrovia e as condicionantes locais;

(iii) identificar os procedimentos de análise e proteçáo realizados pela Empresa RUMO MALHA SUL S.A., especialmente nas áreas identificadas como Faixa de Domínio, lindeiras à Ferrovia em que são operadas as atividades de transporte;

(iv) analisar a multiplicidade de interesses sobrepostos nas faixas de segurança e de domínio do Sub-ramal da Ferrovia que atravessa o Município de Almirante Tamandaré, considerada a caracterização dos agentes envolvidos, as responsabilidades e as respectivas capacidades de responderem às possíveis soluçôes ou encaminhamentos;

(v) indicar Recomendaçoes Técnicas que possam servir à mitigação dos impactos e riscos decorrentes do aproveitamento ou não aproveitamentos das áreas contíguas à Ferrovia.

A demanda para tal estudo está fundada no escopo da Ação Civil Pública ajuizada pela Defensoria Pública da União, em virtude da defesa de direitos dos moradores ocupantes das áreas lindeiras à Ferrovia, face às açôes de reintegração de posse ajuizadas pela empresa RUMO MALHA SUL S.A..

O estudo desenvolvido e apresentado neste documento náo tem por escopo o questionamento sobre o risco já indicado em estudos realizados pela Agência Nacional de Transportes Terrestres/ANTT — Relatório de Avaliaçấo e Classificação de Risco de Invasóes na faixa de Domínio no município de Almirante Tamandaré/PR e o Relatório n. 102/2019/ COFER/URRS -.

\section{PARTES}

Os interesses sobre as áreas em litígio são diversos e envolvem agentes públicos e privados. Sendo diretamente interessados os seguintes:

. Município de Almirante Tamandaré

. Moradores e outros ocupantes das Faixas de Domínio

. Empresa RUMO MALHA SUL S.A..

Também apresentam alguma relação com as questôes decorrentes da atividade realizada a 
União, a Agência Nacional de Transportes Terrestres, o Estado do Paraná e a COMEC, os Municípios de Curitiba e Rio Branco do Sul, dentre outros agentes públicos e privados.

Além de interesses e direitos individuais e coletivos, dada a natureza e a caracterização da questão apontada na ação judicial, direitos difusos também estão presentes e devem ser considerados na análise.

\section{METODOLOGIA}

A Metodologia utilizada para a análise considerou a complexidade da situação objeto do estudo, a diversidade de elementos e a necessidade de procedimentos de cruzamento de informaçóes, bem como, a contextualização nos tempos e no espaço e a comparação com situaçôes similares.

Do ponto de vista da contextualização do objeto de pesquisa, a Ferrovia foi considerada como atividade impactante, do ponto de vista ambiental, urbanístico, econômico e social, inserida na malha urbana de município de Região Metropolitana que apresenta conurbação com a capital. A análise é, portanto, relacional uma vez que a Ferrovia náo pode ser analisada ou compreendida como elemento hierarquicamente superior a outros elementos componentes das dinâmicas municipais, tampouco, pode subordinar as açóes de todo o Município, ainda que seja considerada, dada a sua natureza e características, elemento importante na análise das dinâmicas municipais, territoriais e de ligação entre municípios.

Sobre os procedimentos de análise adotados na pesquisa foram considerados os seguintes:

\section{(I) Leitura Preliminar de Documentos e Informaçóes Gerais}

Uma vez definido o objeto da pesquisa, fez-se a análise preliminar de informaçóes e documentos sobre:

. Contexto do Objeto:

a) histórico de implantação e uso da Ferrovia;

b) localização e uso do solo na área contígua à Ferrovia;

c) características do Município de Almirante Tamandaré e ligação com outros Municípios.

. Leitura de Políticas de Transportes e Mobilidade e de Conflitos atinentes à Ferrovia:

a) documentos:

Agência Nacional de Transportes Terrestres - ANTT: Relatório de Avaliação e Classificação de Risco de Invasóes na faixa de Domínio no município de Almirante Tamandaré/PR e o Relatório n. 102/2019/COFER/URRS;

Departamento Nacional de Infraestrutura de Transportes - DNIT: PROSEFER Programa Nacional de Segurança Ferroviária em Áreas Urbanas 
Disponíveis em: http://www.antt.gov.br/ferrovias/index.html e http://www.dnit. gov.br/modais-2/ferrovias

b) normas:

normas federais: Política Nacional de Mobilidade Urbana - Lei n. 12587/2012; Estatuto da Cidade - Lei n. 10257/2001; Lei de Parcelamento do Solo - Lei n. 6766/1979; Plano Nacional de Desestatização; Lei de Regularização Fundiária Lei n. 13465/2017; do Decreto n. 7.929/2013:

normas estaduais: Lei Estadual n. 11027/1994.

normas municipais: Uso e Ocupação do Solo - Lei Municipal n. 02/2006, Plano Diretor - Lei Municipal n. 77/2018.

c) documentos judiciais: a Ação Civil Pública proposta pela Defensoria Pública da União, outras açôes com objeto similar, Parecer do Ministério Público Federal.

\section{(II) Procedimento de Vistoria}

Verificação in loco do trecho em estudo (realizado em 29/10/2019), com observação visual do local e edificaçóes, que podem ser vislumbrados nas figuras 7, 8 e 9 e fotografias 1,2 e 3 .

$\mathrm{Na}$ ocasião também foi realizado contato com moradores das áreas contíguas à Ferrovia em que foi lhes perguntado sobre o tempo de ocupaçáo, ocorrência de acidentes e benefícios urbanos da região ocupada.

\section{(III) Análise de Documentos}

Após a análise preliminar de documentos e da Vistoria, a equipe voltou à leitura dos documentos, considerando mais especificamente os elementos concernentes ao objeto da pesquisa.

A pesquisa foi estruturada em três eixos que são relacionados na análise diagnóstica e nas Recomendaçóes Técnicas:

(i) jurídico: análise de legislações, jurisprudência, pareceres e ações judiciais de reintegração de posse;

(ii) mobilidade/transportes: análise de documentos sobre as condiçóes das vias férreas, elementos constituintes, riscos etc. Os documentos analisados foram produzidos e divulgados pela Agência Nacional de Transportes Terrestres - ANTT e Departamento Nacional de Infraestrutura de Transportes - DNIT.

(iii) urbanístico/territorial: análise das condições gerais dos impactos da via sobre a o espaço urbano, relaçóes entre a dinâmica urbana municipal e metropolitana e as atividades causadoras de impactos, análise do plano diretor, uso e ocupação do solo, parcelamento, mobilidade dentre outras questóes.

\section{(IV) Cartografia}


A análise cartográfica e a representação espacial contaram com a utilização da fonte de dados geográficos disposta no site http://infraestrutura.gov.br/. O estudo foi realizado com a base de dados da infraestrutura ferroviária, com o sistema de informações geográficas SIRGAS2000 e com os dados obtidos de Curitiba do site do IPPUC - Instituto de Pesquisa e Planejamento Urbano de Curitiba. As imagens de satélite foram obtidas do Google Earth representando a área em estudo. A análise geográfica foi realizada a partir da sobreposição das imagens com o Ramal da linha Almirante Tamandaré/Curitiba e implementada com a tecnologia de software QGIS, que permite realizar operaçóes georreferenciadas. A vetorização da ferrovia foi desenvolvida com base nas imagens para a geração de buffers (delimitação da área) com espaçamento de 6 metros do eixo da ferrovia para faixa de segurança e de 15 metros do eixo da ferrovia para a faixa de domínio (operacional). A partir do lançamento do georreferenciamento foi possível realizar a análise visual e verificação dos casos críticos de ocupação das faixas. Por fim foram gerados mapas da região conflitante utilizando o sistema de referência WGS 84. A manipulação dos dados em um ambiente de Sistemas de Informação Geográfica (SIG) consistiu na visualização, nas consultas, nas análises e nas simulaçóes dos cenários onde há conflito da ferrovia com o meio urbano.

\section{(V) Outras informaçóes e Entrevistas}

Além das informações disponíveis, a equipe de pesquisa realizou entrevistas com as Secretarias Municipais de Habitação e de Urbanismo e recebeu informações advindas da Defesa Civil do Município.

Como resultados das entrevistas, de cadastros de famílias realizada pela Secretaria de Habitação e de outras informaçóes respondidas via e-mail foram utilizadas na análise:

1. A indicação sobre a inexistência de acidentes no Município, decorrentes do conflito entre usos da ferrovia na faixa de domínio e dos moradores (entrevista e informação da Defesa Civil);

2. Conhecimento do Município sobre as medidas da faixa de domínio e faixa de segurança;

3. Tempo de ocupação das áreas ocupadas da faixa de domínio da Ferrovia;

4. Condiçôes gerais socioeconômicas e de posse consolidada dos moradores.

Também foram consideradas as literaturas técnicas e acadêmicas que abordam o tema, especialmente para a definição das categorias de análise.

\section{(VI) Procedimentos após a análise das fontes de informaçóes}

Após a análise das fontes e da identificação do contexto foi realizado o cruzamento das 
informaçóes e a leitura diagnóstica.

A partir dos resultados do Diagnóstico foram identificadas algumas Recomendaçóes Técnicas. Tais Recomendaçóes não tem por pretensão o esgotamento das medidas mitigatórias ou mesmo a avaliação sobre situaçóes mais definitivas no longo prazo como, por exemplo, o próprio deslocamento da via férrea do centro do Município.

\section{ANÁLISE}

No exame da área em questão foi constatado que a Ferrovia atravessa o município de Almirante Tamandaré, e que isso ocorre em praticamente toda a extensão do perímetro urbano, condicionando parte considerável do território e das atividades da população, mesmo daquela não ocupante da faixa de domínio.

Nesse sentido, para exemplificar um dos impactos mais evidentes da Ferrovia é possível fazer referência aos vários cruzamentos que dificultam e, por vezes, impedem o fluxo da mobilidade no Município.

No caso específico do trecho que apresenta várias residências construídas na faixa de domínio, ou mesmo na faixa de segurança, os riscos podem ser iminentes, a depender de cada caso em relação à Ferrovia, ainda que de acordo com a informação fornecida pelo Município, não exista conhecimento sobre qualquer acidente na área, mais especificamente, nenhuma ocorrência de acidente com moradia foi registrada pela Defesa Civil nos últimos dez anos, inclusive na área do Jardim das Oliveiras.

Também, de acordo com os levantamentos da Secretaria Municipal de Habitação, a convivência entre a Ferrovia e moradias, comércio, infraestrutura, equipamentos e serviços públicos e privados já ocorre há muitos anos, sendo que no caso das moradias, algumas famílias residem na área há mais de vinte anos.

Para ilustrar a situação, podem ser vistas as figuras seguintes, considerando-se que aqui foi arbitrada para fins de facilitar a identificação, uma faixa de segurança geral de seis metros que recai sobre a faixa de domínio. 
Figura 7 - Análise da área de ocupação - Perímetro Urbano Almirante Tamandaré - Ramal Curitiba à Rio Branco do Sul

\section{Análise da Área de Ocupação - PERIMETRO URBANO Ferrovia: Ramal Curitiba - Rio Branco do Sul}

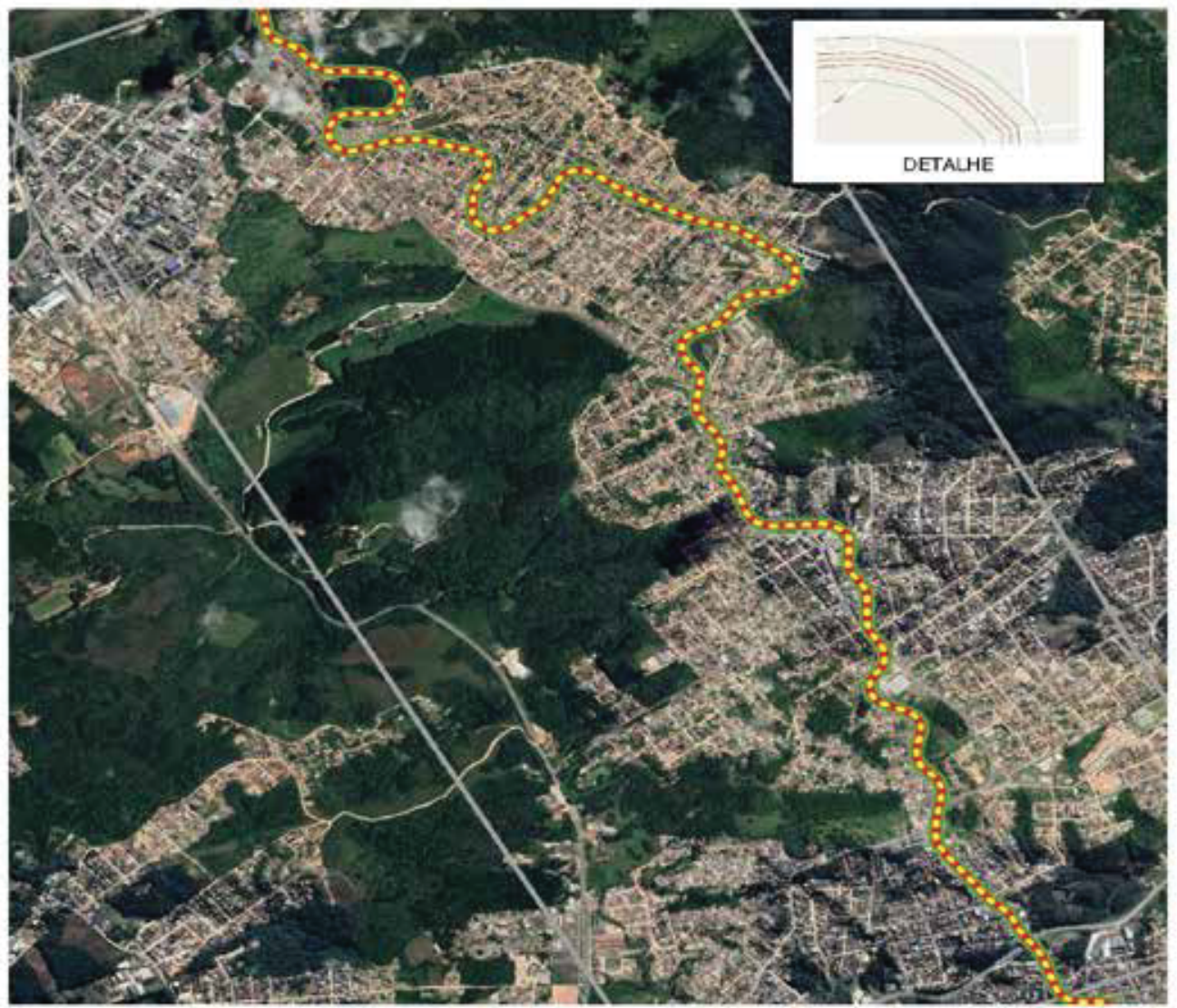

Legenda

Eixo Rodovia

$\square$ faixa_seguranca_ 6 metros

$\square$ faixa_dominio_20 metros

Perimetro Urbano

- - Divisas

Fonte: Ferrovias (Ministerio da Infraestrutura)

Elaboracito: UfPR - 2019

Escala: llustrativa

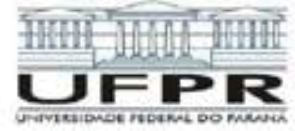

Imagem Google 
Figura 8 - Detalhe 1 de ocupação na faixa de domínio

DETALHE FAIXA DE OCUPACĀO IRREGULAR

Ferrovia: Ramal Curitiba - Rio Branco do Sul

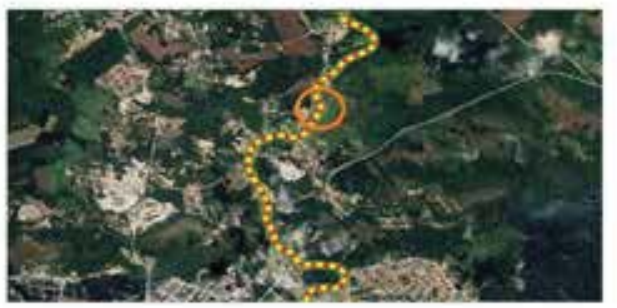

Legenda

$\square$ Aveas ciriticas

ferrovia_poople

$\square$ taba_seguennca_6 metros

$\square$ mika dominio 20 metros.

Imogem coople

Detathe de ocupoctio imegular ns foba de dominia pordin fora to favo de seguranca.
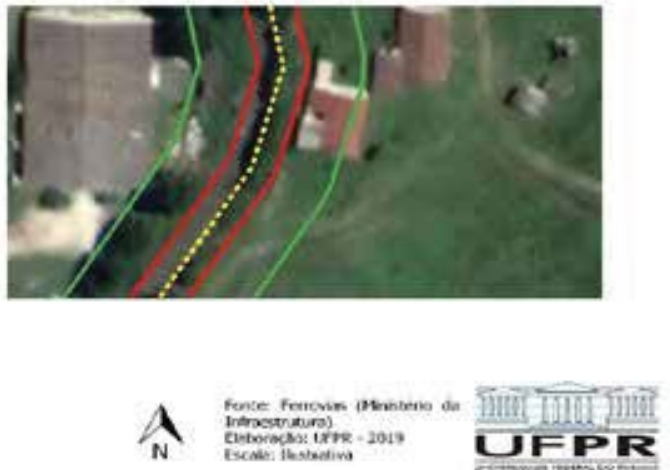

Figura 9 - Detalhe 2 ocupaçóes na faixa de domínio

Parecer Beira Trilho: Ramal Ferroviário Curitiba - Rio Branco do Sul
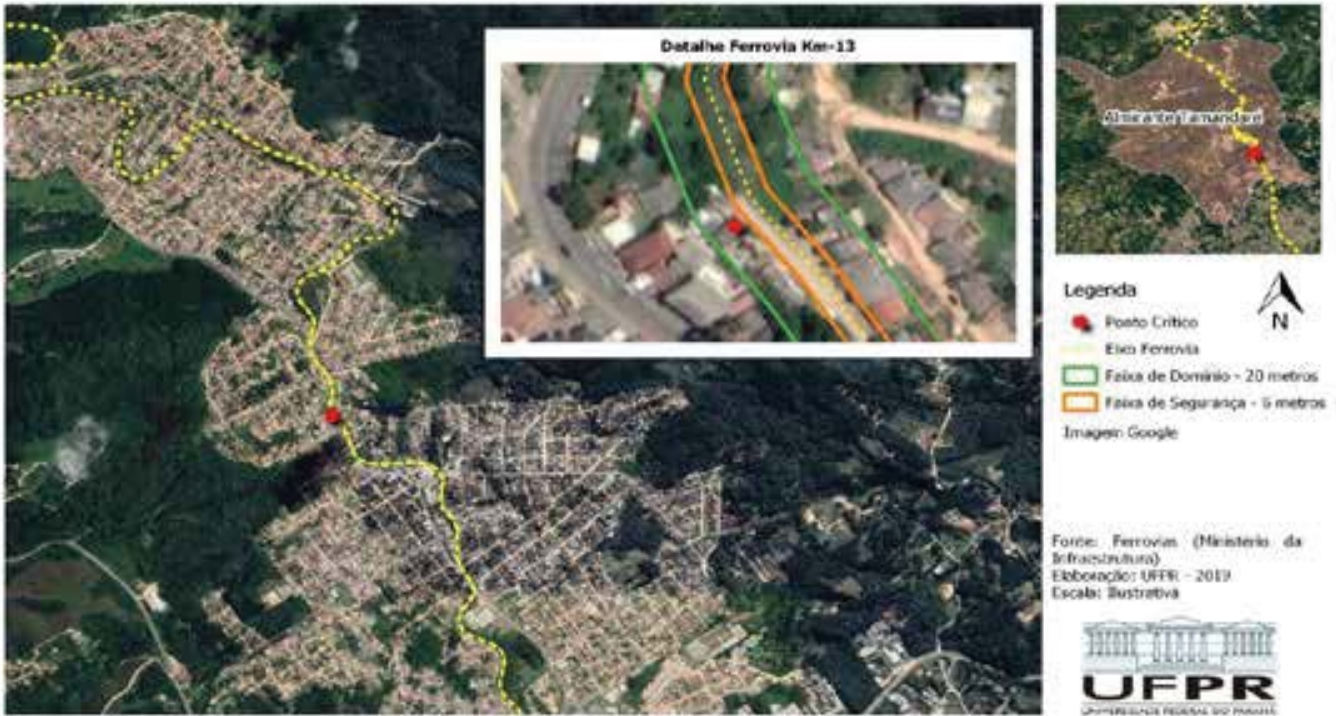

tegenda

4 nomo critice

N

Eive ferent

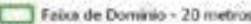

$\square$ raiso de seguricica - 5 metoss

Imoven Goopte

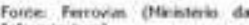

stracintaras

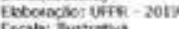

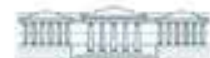

UF ER 
Fotografia 1 - Casas com ocupaçóes na faixa de domínio na área crítica

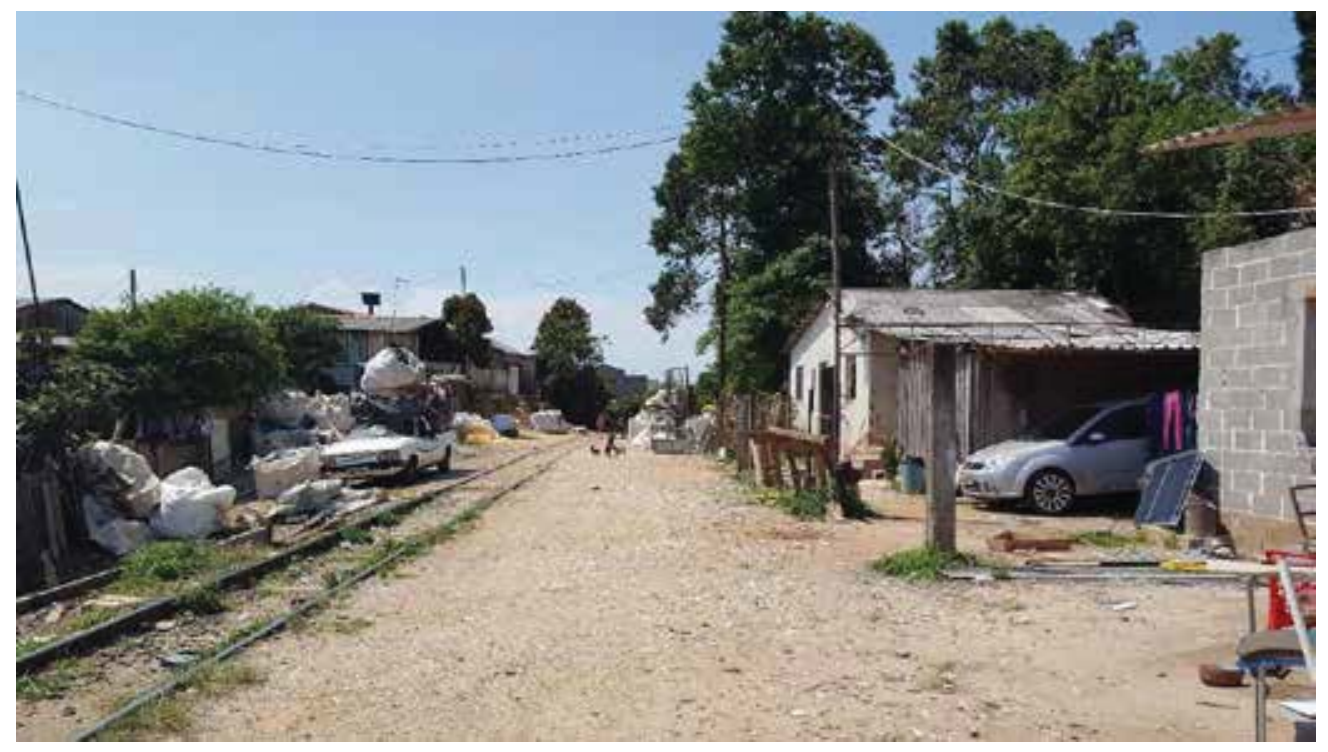

Fotografia 2 - Casas com ocupaçóes na faixa de domínio na área crítica

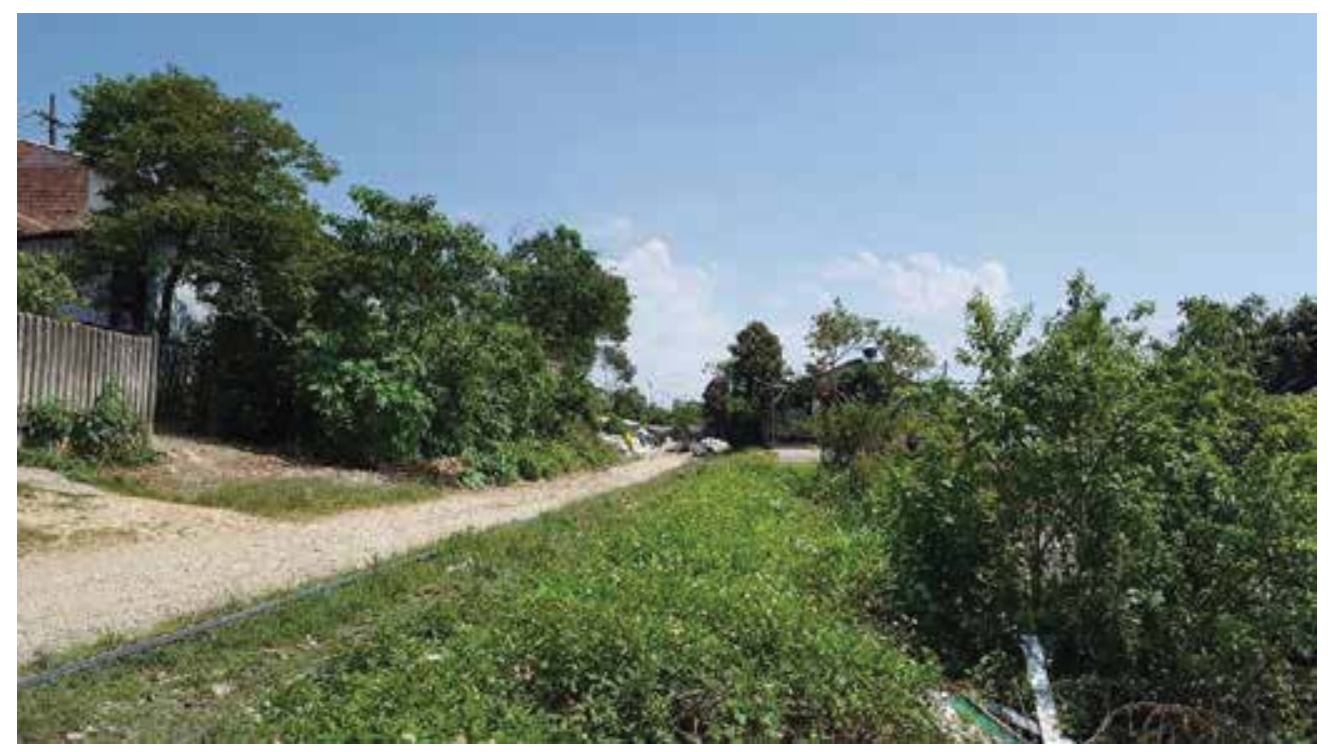




\section{Fotografia 3 - Casas com ocupaçóes na faixa de domínio na área crítica}

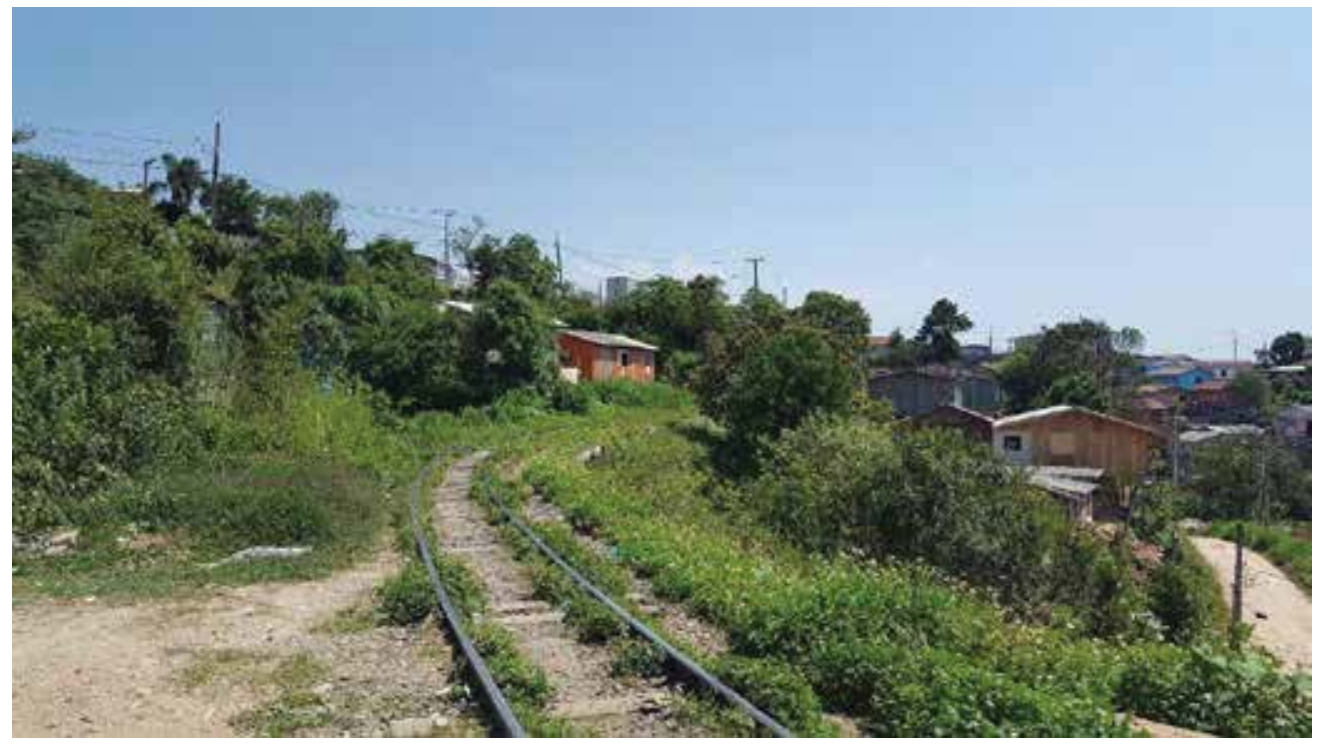

Em contato verbal, alguns moradores relataram que a antiga concessionária, a América Latina Logística (ALL), havia permitido, por meio de acordos judiciais anteriores, que suas residências permanecessem na faixa de domínio, desde que respeitassem uma faixa de segurança arbitrada, assim como o fizeram.

\section{LOCALIZAÇÁO E HISTÓRICO DA ÁREA DE ESTUDO}

O trecho compreendido da Ferrovia que é foco do presente estudo está localizado na malha sul do País e está concedido atualmente à empresa Rumo Malha Sul S.A..

A Ferrovia atravessa o município de Almirante Tamandaré, e é compreendida como um sub-ramal secundário (com menor expressividade) fazendo parte da ligação intermediária do município de Rio Branco do Sul e Curitiba, e acessando o trecho mais expressivo somente na cidade de Curitiba, no Corredor 5 (Maringá - Apucarana - Ponta Grossa - Curitiba - Paranaguá). A Figura 01 apresenta o mapa ferroviário, com os principais corredores do País. 
Figura 1 - Mapa ferroviário do Brasil principais corredores

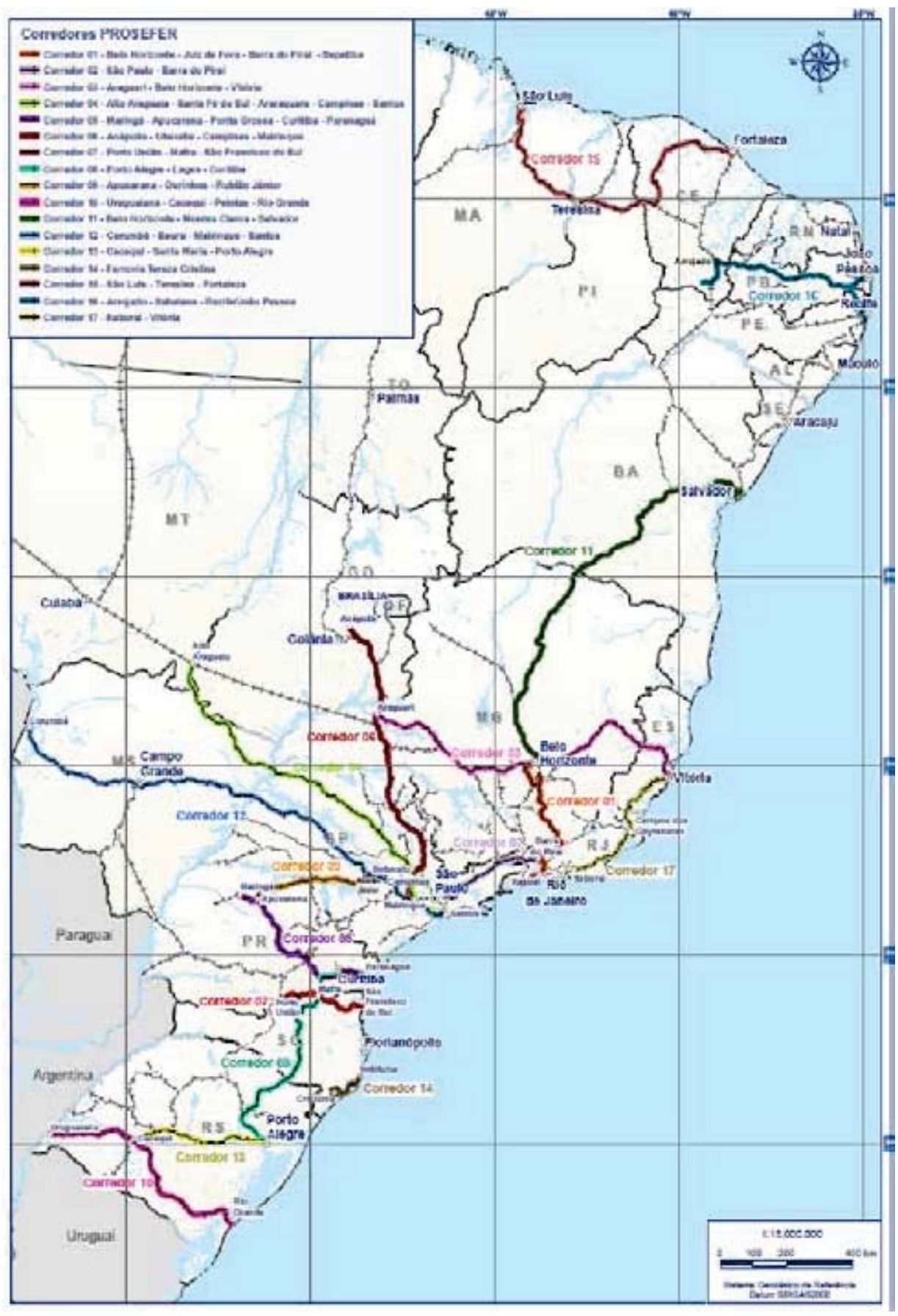

Fonte: (Agência Nacional de Transportes Terrestres - ANTT, 2014.

Proposições para solução de conflitos ferroviários. Brasília, DF). 
A malha sul de modo geral possui em sua extensão trechos de bitola larga $(1,60 \mathrm{~m})$ e de bitola mista (entre $1,00 \mathrm{~m}$ a $1,60 \mathrm{~m}$ ). A rede da malha sul possui ao todo uma extensão de $7.223 \mathrm{~km}$. O Corredor 5, conforme já citado, que compete à malha sul, transporta em média 103.126.461 toneladas útil, passando por uma população de 2.718 .572 habitantes. (Agência Nacional de Transportes Terrestres - ANTT, 2014. Proposiçôes para solução de conflitos ferroviários. Brasília, DF). A Figura 2 apresenta o mapa de situação da malha sul

Figura 2 - Mapa de Situaçáo Malha Sul

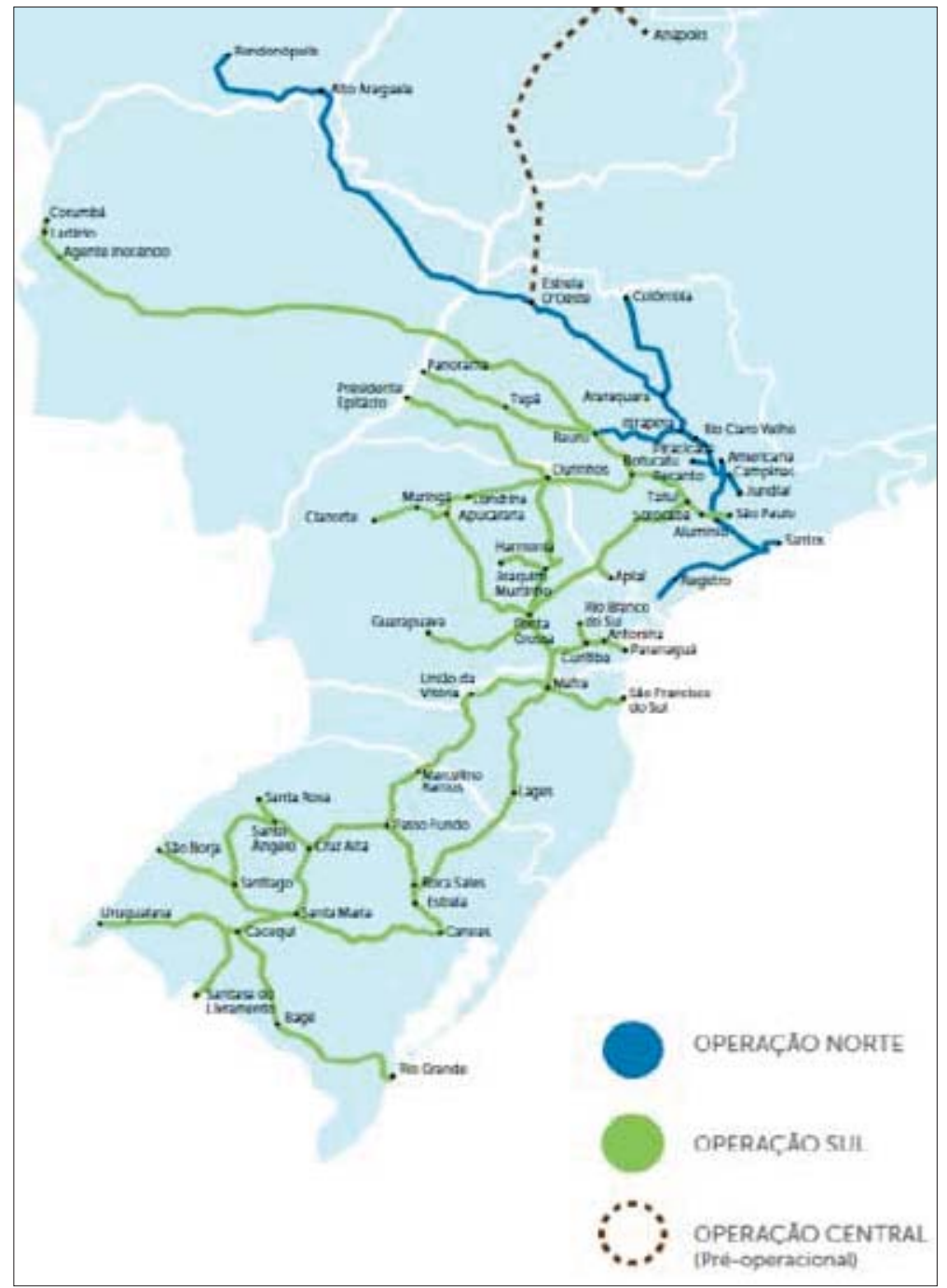

Fonte: http://ri.rumolog.com/ptb/10057/2019_09_30_RUMO_RAS2018.pdf 
O município de Almirante Tamandaré, possui população estimada em 2019 de 118.623 habitantes conforme dados do Censo do Instituto Brasileiro de Geografia e Estatística (IBGE). O município está situado no sudeste do Estado do Paraná, compreendido na Regiāo Metropolitana de Curitiba. A sede municipal dista 17 quilômetros ao norte da capital do estado por rodovia. Almirante Tamandaré faz divisa ao norte com Itaperuçu e Rio Branco do Sul, ao sul com Curitiba, a leste com Colombo e a oeste com Campo Magro. Sua área é de $195 \mathrm{~km}^{2}$ (Figura 3).

Figura 3 - Ramal ferroviário de Curitiba à Rio Branco do Sul

\section{Análise da Área de Ocupação de Faixa de Domínio e Faixa de Segurança da Ferrovia: Ramal Curitiba - Rio Branco do Sul}

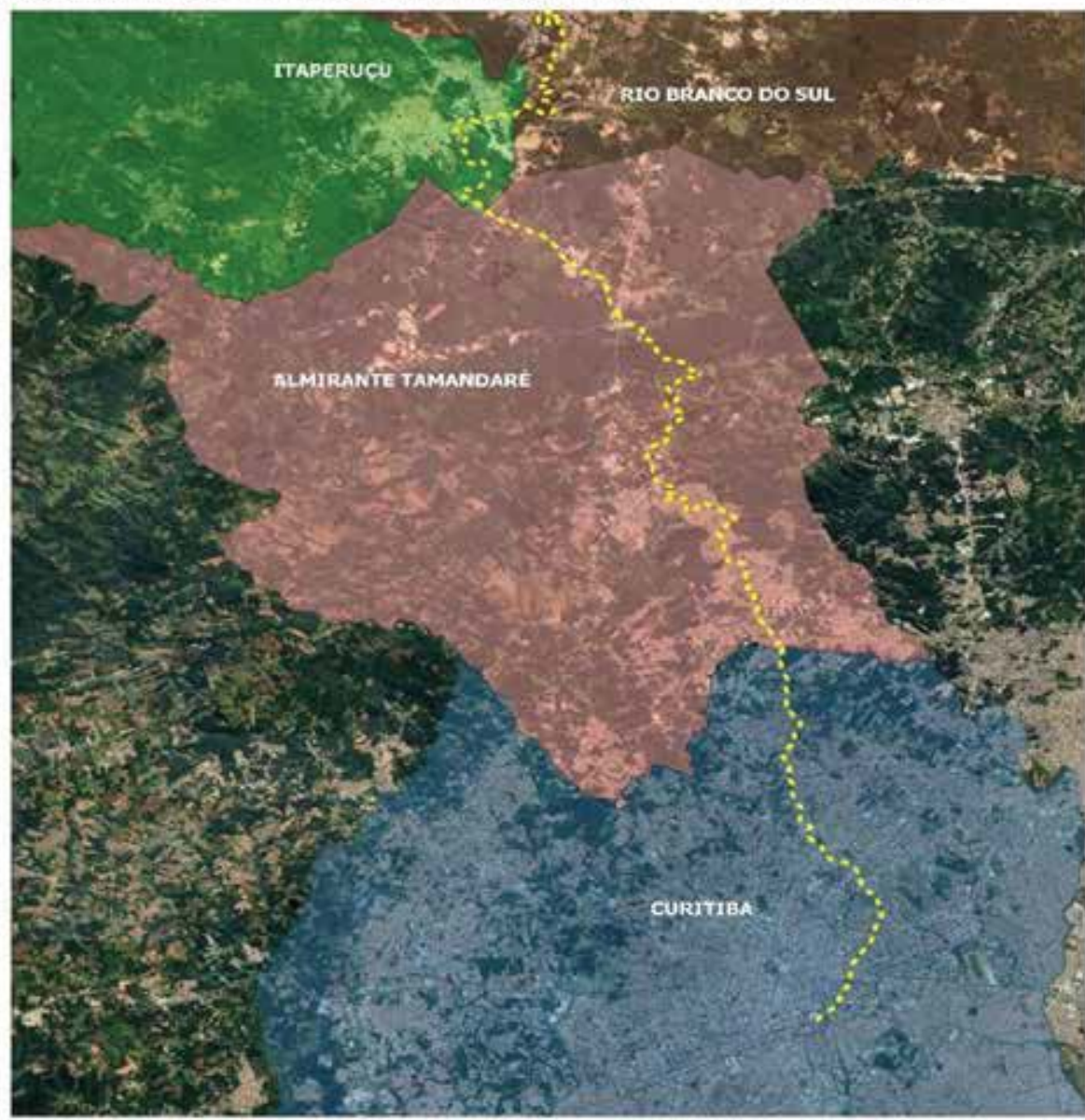

\section{Legenda}

-.- Ramal_Curitiba_Rio Branco do Sul Imagem Google

Fonte: Ferrovias (Ministerio da 
A ferrovia compreende um Sub-ramal curto, que parte da estação de Curitiba, com apenas $42 \mathrm{~km}$ de extensão. De acordo com as informações levantadas no site "Estações Ferroviárias do Brasil", de Ralph Mennucci Giesbrecht atualizada em 19/02/2018, não haveria demanda por via férrea se nos anos 1940, não tivesse sido construída na sua extremidade uma fábrica de cimento, que hoje pertence ao Grupo Votorantim. O ramal, que teve trens de passageiros até 12 de janeiro de 1991, já funcionando como trens de subúrbio, atualmente segue funcionando com trens cargueiros que transportam cimento. Esses veículos cruzam toda a zona nordeste de Curitiba até hoje, com passagens de nível somente em ruas de grande movimento (http://www.estacoesferroviarias.com.br/pr-riobranco/almtamandare.htm).

Também o blog "Vida Dmaquinista” também explica o histórico da Ferrovia, conforme segue:

As chácaras ao longo da estrada de ferro, nas décadas de 1950 e 1960, passaram por um processo de urbanizaçáo, com loteamentos despontando em todo o trecho, dando origem aos atuais bairros do Cristo Rei, Alto da XV, Hugo Lange, Cabral, Boa Vista, Barreirinha e Cachoeira. Com mais pessoas morando ao longo da via, o transporte de mercadorias foi se separando do transporte de passageiros. Os trens mistos foram substituídos pelos trens de carga e pelos trens expressos, exclusivos para passageiros. Na década de 1950, o trem expresso foi chamado de trem de subúrbio, que encerrou suas atividades em 12 de janeiro de 1991. A linha perdia sua funçáo social, motivo mesmo de sua construçáo. Hoje, ainda em funcionamento, o ramal é praticamente um grande desvio particular para as operaçóes de transporte de uma grande empresa de cimento. Atravessando, dentro dos limites da cidade, regióes habitadas por pessoas de diferentes classes sociais, o trem não conta mais com a simpatia de muitos moradores.

A substituição das marias-fumaças por locomotivas diesel-elétricas, na década de 1950, multiplicou o poder de tração e o tamanho das composiçóes. No mesmo passo, o som cheio e agradável dos apitos foi substituído pela potência ensurdecedora das buzinas pneumáticas. Sem relaçáo com as comunidades que cruza, mais pesado e barulhento, o trem neste ramal se apresenta hoje cortando a paisagem social de forma agressiva. Mas na memória de muitos moradores permanecem as lembranças do caráter social da estrada, tanto por ter transportado trabalhadores, quanto por ter carregado os produtos de subsistência dos produtores locais - o que lhe rendeu o simpático apelido de "ferrovia das galinhas".

É interessante destacar que, enquanto esse ramal sublinhava ocupaçôes já existentes, a estrada de ferro que liga Curitiba a Paranaguá viabilizou o surgimento de núcleos urbanos. (Http://vidadmaquinista.blogspot. com/2012/04/quatro-horas-da-madrugada.html).

De acordo com o relato, o histórico do ramal ferroviário, as vilas, moradias e ocupações já existiam desde à época das primeiras operaçóes ferroviárias naquele trecho. Essa informação foi corroborada nas entrevistas com a população e com representantes e servidores do município de Almirante Tamandaré. O que denota a necessidade de observação sobre a posse e suas qualidades, como por exemplo, o fato dessa se apresentar na área lindeira à Ferrovia, provavelmente na condição de posse justa, de boa-fé e velha, o que apresenta 
impacto no trato das construçôes e benfeitorias que não se confundem necessariamente com a situação da terra, mas que com ela apresentam relação, conforme disposto no Código Civil, Lei Federal n. 10406/2002. Nesse sentido, verificar Anexo - documento que trata do levantamento das famílias realizado pela Secretaria Municipal de Habitaçáo e que já declara a consolidação de diversas moradias na faixa de domínio da Ferrovia.

Atualmente o trecho alimenta as empresas privadas, cortando áreas urbanas e rurais, interferindo diretamente nas características da cidade e representando ônus ao poder público e moradores, especialmente do ponto de vista da urbanização.

\section{CARACTERÍSTICAS DA ÁREA E OPERAÇÃo}

Para a melhor elucidação das características das áreas contíguas à Ferrovia, entende-se as categorias de análise, a partir das definiçóes do DNIT e da ANTT. Existem diferentes faixas contempladas no debate sobre suas respectivas titularidades e sobre suas respectivas funçóes de acordo com a página 23 do Glossário de Termos Ferroviários do DNIT, Disponível em: https://189.9.128.64/ferrovias/glossario-de-termos-ferroviarios/glossario.pdf

- Faixa de domínio a porção de terreno com largura mínima de cada lado do eixo da via férrea, sem prejuízo das dimensôes estipuladas nas normas e regulamentos técnicos vigentes, ou definidas no projeto de desapropriação ou de implementaçáo da respectiva ferrovia ou, nos termos do DNIT, "faixa de terreno de pequena largura em relação ao comprimento, em que se localizam as vias férreas e demais instalaçôes da ferrovia, inclusive os acréscimos necessários à sua expansão”.

A faixa de domínio comporta pelo menos três faixas diferentes:

(i) Área de escape ou faixa de segurança caracterizada por estar diretamente afeta ao risco;

(ii) Faixa de domínio operacional - de manutenção e serviços atinentes à ferrovia;

(iii) Faixa de Domínio não operacional - de projetos atinentes à ferrovia.

De acordo com o que define o artigo $1^{\circ}$, parágrafo $2^{\circ}$ do Decreto $n^{\circ} 7.929 / 2013$ a faixa de domínio é variável e o Relatório da ANTT não trata da faixa de domínio, mas, de faixa de segurança (ou de escape) atinente aos riscos da proximidade de edificaçóes que apresentam como uso a moradia.

Art. $1^{\circ}$

$\$ 2^{\circ}$ Para efeito deste Decreto, entende-se por faixa de domínio a porção de terreno com largura mínima de quinze metros de cada lado do eixo da via férrea, sem prejuízo das dimensôes estipuladas nas normas e regulamentos técnicos vigentes, ou definidas no projeto de desapropriação ou de implementação da respectiva ferrovia.

Em virtude disso, segue o debate sobre o conceito de faixa de segurança ou de escape.

- Faixa de segurança, de serviço ou de escape a definida como a área mínima de terreno necessária 
para a segurança do tráfego de trens. Via de regra, corresponde a 6 (seis) metros contados da linha do trem, porém, esse dado não foi acessado durante a pesquisa, inclusive porque de acordo com os entrevistados "nem o próprio município dispóe dessa informação com exatidão". Além disso, a "Classificação de Risco às Pessoas" constante de Relatório do DNIT, referente à Açáo Civil Pública, trata provavelmente do mapeamento da distância entre as edificaçóes e a Ferrovia, de modo que os dados trazidos náo fazem referência exata à faixa de domínio e sua caracterizaçáo, ainda que o documento informe que usou as plantas e documentos da extinta RFFSA no lançamento da faixa de domínio. Como se pode verificar no "Quadro Resumo" do Relatório do DNIT, a "Distância Mínima" varia entre dois e quinze metros em trechos que podem ter apresentar distâncias menores de um quilômetro, o que faz supor que o estudo tratou da distância mínima das edificaçôes em relaçáo à ferrovia e não exatamente da área estabelecida como faixa de domínio. De qualquer modo, essa questão deve ser esclarecida pelo próprio DNIT, pois esse fator implica na leitura sobre o risco e sobre as possíveis mitigaçôes, inclusive porque não é possível saber, pela metodologia utilizada, qual o fator determinante ou preponderante para aferição da classificação de risco. Nesse sentido, foram considerados os seguintes fatores:

(i) Distância das habitaçôes ao eixo da linha férrea: quanto menor a distância maior o risco;

(ii) Nível do piso das habitações em relação ao nível da linha férrea, sendo o risco é menor na medida em que está acima do nível da linha férrea;

(iii) Localização em Curva: a probabilidade de tombamento é maior nas curvas do que nas tangentes;

(iv) Volume de tráfego calculado por tonelada útil, sendo que quanto maior o volume de tráfego, maior o risco;

(v) Transporte de produtos perigosos.

Como se verá adiante, o último item "transporte de produtos perigosos" não caracteriza a situação da Ferrovia que transporta cimento (e não combustível, por exemplo), de modo que não se sabendo qual é o fator de risco, fica mais difícil identificar a questão da segurança e, portanto, das faixas. De qualquer modo, o estudo aqui apresentado leva em consideração a classificação final proposta pela ANTT, porque o risco de proximidade com ferrovia de fato é plausível.

- rea náo edificável corresponde a 15 (quinze) metros de largura, contados a partir do término da faixa de domínio. Trata-se de uma limitação administrativa aos loteamentos, imposta à propriedade particular. Não transforma o terreno em bem público e nem determina a posse ou a propriedade da União sobre o bem. Visa impedir que particulares construam dentro desta área.

No caso de Almirante Tamandaré, a soma das duas faixas, de domínio e não edificável provocaria um despejo de grandes proporçôes para o Município na sua área mais urbanizada, o que afetaria sobremaneira a própria racionalidade do uso do recurso público e dos benefícios da urbanização, pois, essas áreas estariam sobrepostas exatamente na área com mais serviços, equipamentos e infraestrutura urbana pública, tal como em outra medida já acontece com as áreas denominadas faixas de domínio da ferrovia.

A figura 4 representa o ramal de ligação do trecho que passa pelo perímetro urbano de Almirante Tamandaré, onde pode ser observado que as margens da ferrovia são ocupadas ao longo de quase todo o seu perímetro urbano, onde ocorreu a urbanização e desenvolvi- 
mento local e a Figura 5 apresenta detalhe da faixa de domínio junto com a faixa de segurança de um segmento no perímetro urbano (PU) de Almirante Tamandaré. Cabe ressaltar ainda, que na maioria dos casos, a proximidade entre as edificaçóes e a Ferrovia supera seis metros, ainda que existam construçóes em área de maior proximidade com a Ferrovia.

Também como medida de segurança viária, ao passar por trechos urbanos, ou passagens de nível (PN's), os trens devem fazer uso do sino da locomotiva (se houver) e não exceder velocidade de $10 \mathrm{~km} / \mathrm{h}$ até ocupar a PN. A seguir, os trens retomam a velocidade de $20 \mathrm{~km} / \mathrm{h}$, não superior à Velocidade Máxima Autorizada (VMA), e nos demais trechos cumpre-se a VMA, que depende da classe da ferrovia. Essas medidas visam aumentar a segurança e integridade das operaçóes ferroviárias (RUMO. Regulamento Operacional R.O. Edição - 10/2015. Curitiba, PR.).

Essas informaçóes não foram apresentadas e em visita no local não foram vistas ou pelo menos não estavam evidenciadas as medidas de segurança, tal como sinalização, obras de contenção de acidentes etc.

\section{Figura 4 - Área de ocupação de faixa de domínio e faixa de segurança da ferrovia: Ramal Curitiba a Rio Branco do Sul}

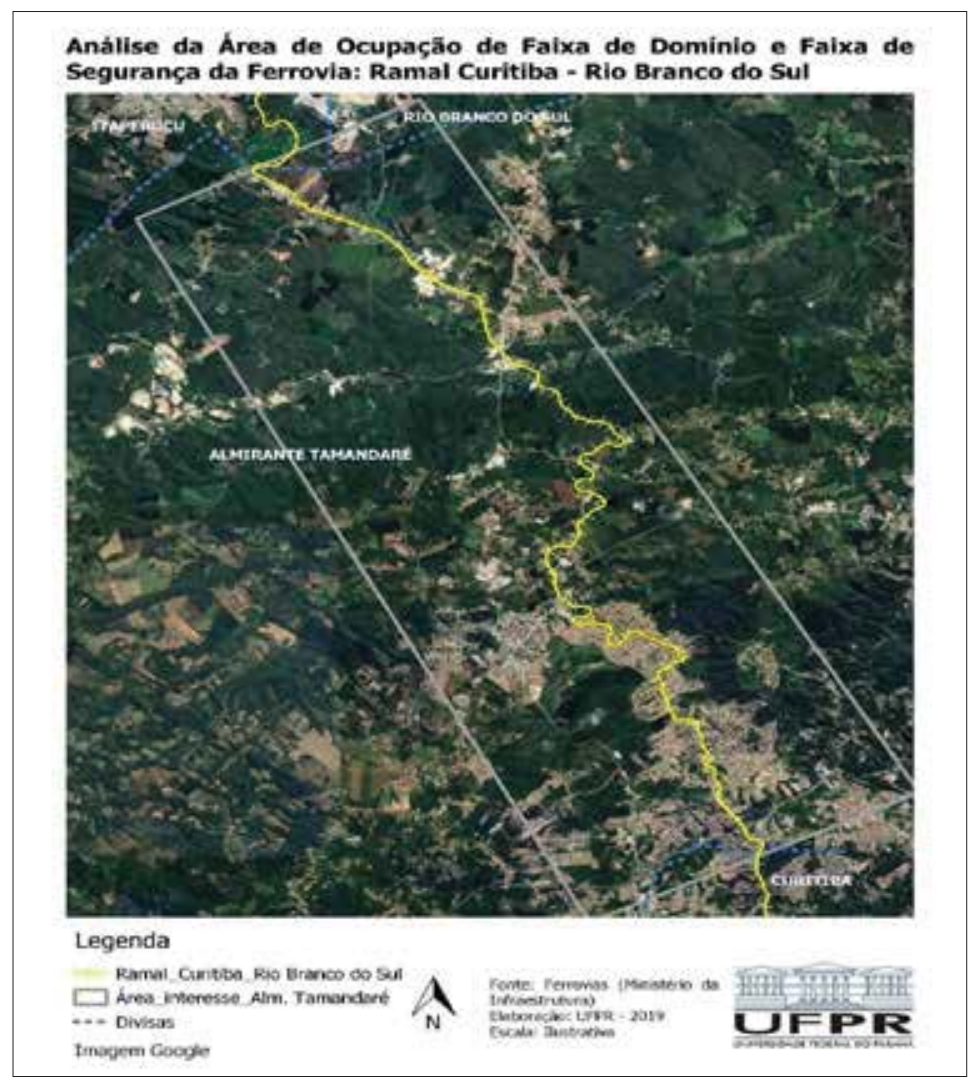




\section{Figura 5 - Trecho de ocupaçáo da faixa de domínio e da faixa de segurança}

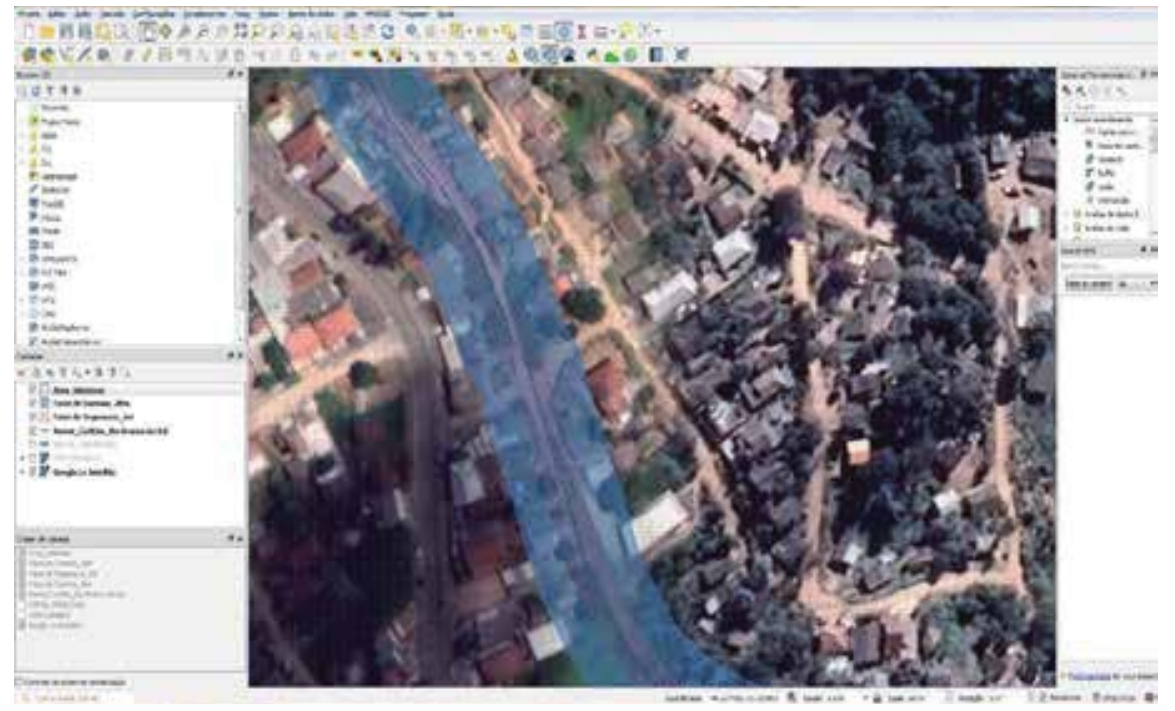

Salienta-se que entre os potenciais econômicos do município, encontra-se a atividade extrativa mineradora, com cerca de 20 indústrias de cal e calcário na regiáo. Conforme o Anuário estatístico de produção origem/destino da ANTT (2018) para ferrovias, o tipo de mercadoria que é mais transportado no ramal que inicia em Rio Branco do Sul e passa por Almirante Tamandaré chegando à Curitiba e escoa sua produção para o Corredor 5 é basicamente o cimento acondicionado, conforme trecho situado na Figura 6. O tipo de mercadoria e suas respectivas quantidades podem ser visualizada na Tabela 1.

Figura 6 - Mapa de Localizaçáo

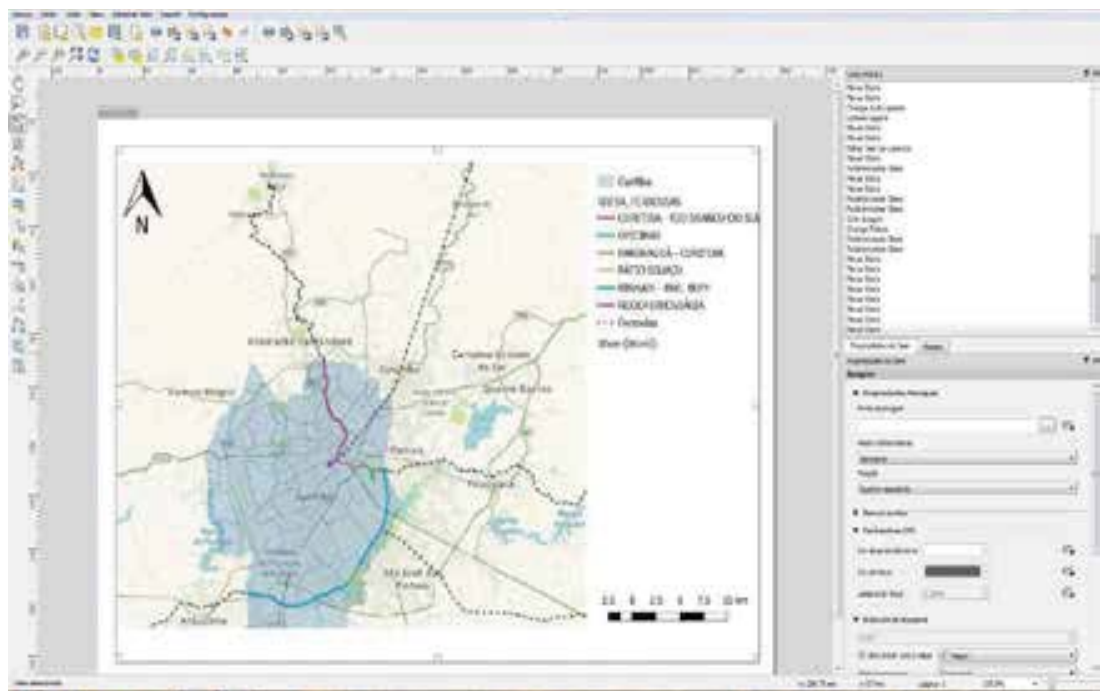

Fonte: Adaptada da Malha Sul 
Tabela 1 - Mercadoria transportada de origem-destino

\begin{tabular}{|c|c|c|c|c|c|c|c|c|}
\hline & & & Origem & & Destino & & & \\
\hline Mês/Ano & Ferrovia & Mercadoria ANTT & Estação & UF & Estação & UF & TU & TKU \\
\hline $01 / 2019$ & RMS & $\begin{array}{c}\text { Cimento } \\
\text { acondicionado }\end{array}$ & $\begin{array}{l}\text { Rio Branco } \\
\text { do Sul }\end{array}$ & PR & Cascavel & PR & 8.865 & 6.076 .975 \\
\hline $01 / 2019$ & RMS & $\begin{array}{c}\text { Cimento } \\
\text { acondicionado }\end{array}$ & $\begin{array}{c}\text { Rio Branco } \\
\text { do Sul }\end{array}$ & PR & Londrina & PR & 10.571 & 6.149 .266 \\
\hline $01 / 2019$ & RMS & $\begin{array}{c}\text { Cimento } \\
\text { acondicionado }\end{array}$ & $\begin{array}{l}\text { Rio Branco } \\
\text { do Sul }\end{array}$ & PR & Maringá & PR & 17.073 & 10.285 .799 \\
\hline 02/2019 & RMS & $\begin{array}{c}\text { Cimento } \\
\text { acondicionado }\end{array}$ & $\begin{array}{l}\text { Rio Branco } \\
\text { do Sul }\end{array}$ & PR & Cascavel & PR & 6.030 & 4.133 .577 \\
\hline 02/2019 & RMS & $\begin{array}{c}\text { Cimento } \\
\text { acondicionado }\end{array}$ & $\begin{array}{l}\text { Rio Branco } \\
\text { do Sul }\end{array}$ & PR & Londrina & PR & 12.353 & 7.185 .875 \\
\hline $02 / 2019$ & RMS & $\begin{array}{c}\text { Cimento } \\
\text { acondicionado }\end{array}$ & $\begin{array}{c}\text { Rio Branco } \\
\text { do Sul }\end{array}$ & PR & Maringá & PR & 17.250 & 10.392 .435 \\
\hline 03/2019 & RMS & $\begin{array}{c}\text { Cimento } \\
\text { acondicionado }\end{array}$ & $\begin{array}{c}\text { Rio Branco } \\
\text { do Sul }\end{array}$ & PR & Cascavel & PR & 6.568 & 4.502 .377 \\
\hline $03 / 2019$ & RMS & $\begin{array}{c}\text { Cimento } \\
\text { acondicionado }\end{array}$ & $\begin{array}{l}\text { Rio Branco } \\
\text { do Sul }\end{array}$ & PR & Londrina & PR & 12.740 & 7.410.998 \\
\hline $03 / 2019$ & RMS & $\begin{array}{c}\text { Cimento } \\
\text { acondicionado }\end{array}$ & $\begin{array}{l}\text { Rio Branco } \\
\text { do Sul }\end{array}$ & PR & Maringá & PR & 18.103 & 10.906 .333 \\
\hline 04/2019 & RMS & $\begin{array}{c}\text { Cimento } \\
\text { acondicionado }\end{array}$ & $\begin{array}{c}\text { Rio Branco } \\
\text { do Sul }\end{array}$ & PR & Cascavel & PR & 6.959 & 4.770 .408 \\
\hline $04 / 2019$ & RMS & $\begin{array}{c}\text { Cimento } \\
\text { acondicionado }\end{array}$ & $\begin{array}{l}\text { Rio Branco } \\
\text { do Sul }\end{array}$ & PR & Londrina & PR & 11.977 & 6.967 .152 \\
\hline $04 / 2019$ & RMS & $\begin{array}{c}\text { Cimento } \\
\text { acondicionado }\end{array}$ & $\begin{array}{c}\text { Rio Branco } \\
\text { do Sul }\end{array}$ & PR & Maringá & PR & 18.378 & 11.072 .009 \\
\hline 05/2019 & RMS & $\begin{array}{c}\text { Cimento } \\
\text { acondicionado }\end{array}$ & $\begin{array}{c}\text { Rio Branco } \\
\text { do Sul }\end{array}$ & PR & Cascavel & PR & 6.533 & 4.478 .384 \\
\hline $05 / 2019$ & RMS & $\begin{array}{c}\text { Cimento } \\
\text { acondicionado }\end{array}$ & $\begin{array}{c}\text { Rio Branco } \\
\text { do Sul }\end{array}$ & PR & Londrina & PR & 12.905 & 7.506 .980 \\
\hline $05 / 2019$ & RMS & $\begin{array}{c}\text { Cimento } \\
\text { acondicionado }\end{array}$ & $\begin{array}{l}\text { Rio Branco } \\
\text { do Sul }\end{array}$ & PR & Maringá & PR & 17.586 & 10.594 .861 \\
\hline $06 / 2019$ & RMS & $\begin{array}{c}\text { Cimento } \\
\text { acondicionado }\end{array}$ & $\begin{array}{c}\text { Rio Branco } \\
\text { do Sul }\end{array}$ & PR & Cascavel & PR & 6.512 & 4.463 .989 \\
\hline $06 / 2019$ & RMS & $\begin{array}{c}\text { Cimento } \\
\text { acondicionado }\end{array}$ & $\begin{array}{l}\text { Rio Branco } \\
\text { do Sul }\end{array}$ & PR & Londrina & $\mathrm{PR}$ & 12.568 & 7.310 .943 \\
\hline $06 / 2019$ & RMS & $\begin{array}{c}\text { Cimento } \\
\text { acondicionado }\end{array}$ & $\begin{array}{l}\text { Rio Branco } \\
\text { do Sul }\end{array}$ & PR & Maringá & PR & 20.207 & 12.173 .909 \\
\hline 07/2019 & RMS & $\begin{array}{c}\text { Cimento } \\
\text { acondicionado }\end{array}$ & $\begin{array}{c}\text { Rio Branco } \\
\text { do Sul }\end{array}$ & PR & Cascavel & PR & 7.380 & 5.059 .004 \\
\hline 07/2019 & RMS & $\begin{array}{c}\text { Cimento } \\
\text { acondicionado }\end{array}$ & $\begin{array}{c}\text { Rio Branco } \\
\text { do Sul }\end{array}$ & PR & Londrina & PR & 11.613 & 6.755 .409 \\
\hline 07/2019 & RMS & $\begin{array}{c}\text { Cimento } \\
\text { acondicionado }\end{array}$ & $\begin{array}{l}\text { Rio Branco } \\
\text { do Sul }\end{array}$ & PR & Maringá & PR & 19.308 & 11.632 .297 \\
\hline 08/2019 & RMS & $\begin{array}{c}\text { Cimento } \\
\text { acondicionado }\end{array}$ & $\begin{array}{c}\text { Rio Branco } \\
\text { do Sul }\end{array}$ & PR & Cascavel & PR & 10.199 & 6.991 .434 \\
\hline 08/2019 & RMS & $\begin{array}{c}\text { Cimento } \\
\text { acondicionado }\end{array}$ & $\begin{array}{c}\text { Rio Branco } \\
\text { do Sul }\end{array}$ & PR & Londrina & PR & 11.989 & 6.974 .133 \\
\hline 08/2019 & RMS & $\begin{array}{c}\text { Cimento } \\
\text { acondicionado }\end{array}$ & $\begin{array}{c}\text { Rio Branco } \\
\text { do Sul }\end{array}$ & PR & Maringá & PR & 22.443 & 13.521 .009 \\
\hline
\end{tabular}

Fonte: http://www.antt.gov.br/ferrovias/arquivos/Anuario_Estatistico.html 
- Risco está compreendido na potencialidade de dano decorrentes de atividades humanas. De acordo com o art, 927 do Código Civil

Art. 927. Aquele que, por ato ilícito ( arts. 186 e 187 ), causar dano a outrem, fica obrigado a repará-lo.

Parágrafo único. Haverá obrigação de reparar o dano, independentemente de culpa, nos casos especificados em lei, ou quando a atividade normalmente desenvolvida pelo autor do dano implicar, por sua natureza, risco para os direitos de outrem.

$\mathrm{O}$ ato ilícito supera as situaçôes de negligência, imprudência ou imperícia, bem como pode se dar nos casos de abuso no exercício de um direito, além disso, o parágrafo único do mesmo artigo trata das atividades que são potencialmente geradoras de dano, caso esse que pode ser verificável naquelas concernentes às ferrovias.

Também cabe a verificação de que o risco na atividade de transporte nesse sub-ramal, além de individual e coletivo, também é difuso, pois provoca efeitos para todo o Município e, ainda, para os municípios atrelados diretamente à Almirante Tamandaré.

Outro ponto do tratamento da questão do risco diz respeito à sua forma de eliminação ou mitigação. No caso em questão, a empresa assumiu que a demanda do despejo seria suficiente do ponto de vista de sua responsabilidade para conter o problema. Ocorre que a medida proposta, o despejo, também é geradora de risco. Desse modo, só aparentemente ou superficialmente o problema seria resolvido, pois, o risco, ainda que reestabelecido em outros termos, persistiria para as famílias, talvez, em alguns casos, agravados pelas condições impostas pelo próprio despejo. Nesse sentido, vale lembrar que de acordo com o levantamento da Secretaria Municipal de Habitação, as famílias são de baixa renda ou baixíssima renda, além disso, muitos vivem no local há muito tempo, o que significa que construíram o seu patrimônio na área. Por fim, há um número expressivo de crianças e adolescentes que usam os serviços próximos ao local de moradia e que seriam diretamente prejudicados em uma remoção em que não fossem consideradas as proximidades de serviços e equipamentos públicos que são significativas da manutenção de vida e de sociabilidade e, principalmente a garantia de habitação e habitabilidade e proximidade com o trabalho, já que o custo com deslocamento é muito significativo.

Sendo assim, deve-se considerar nos casos em que for necessária a remoção em virtude do risco iminente, a responsabilidade da empresa sobre o plano de remoção com atendimento às famílias, definição da nova localização das casas, considerada a proximidade com as áreas atualmente ocupadas, além de evidentemente ocorrer a caracterização da medida como pertinente e urgente em virtude do risco.

Concluindo, tal como a classificação de risco às pessoas em virtude da proximidade da Ferrovia, deve-se realizar a Classificação de Risco de Despejo, de modo a não se repetir a ação de impacto e risco afastada.

Outro aspecto analisado diz respeito à metodologia de estudo da ferrovia em que se constata que é rotineira a prática da análise sistêmica nas questóes afetas a própria ferrovia. Para a análise da atividade esta é isolada e os aspectos que implicam na realização ideal do 
seu exercício e finalidade não são tratados na relação com o ambiente. Desse modo, ocorre certa hierarquização da atividade em relação ao ambiente.

No caso concreto do sub-ramal isso também ocorre. A cidade e a população nos estudos, ficaram subordinados à função-ótima da Ferrovia. Ocorre que a Ferrovia está em local inadequado para o seu funcionamento, portanto, ela deve ser estudada nas relaçóes que estabelece com o meio, no caso, com a área urbana do Município de Almirante Tamandaré. Isso não significa limites à urbanização em áreas de risco, mas, medidas de segurança adequadas àquele espaço. Nestes estudos realizados, não foram encontrados e, portanto, analisados os estudos de impacto da Ferrovia sobre a cidade, tal como, por exemplo, o estudo de impacto de vizinhança. Nesse estudo, a Ferrovia busca a forma de melhor se integrar à cidade, inclusive porque os riscos não estão adstritos à proximidade apenas de moradias, mas, também de comércios, de mobilidade, ambientais em virtude das questóes geológicas kársticas em partes do território do Município, da densidade populacional e construtiva em virtude da área metropolitana, do tratamento entre as áreas de ocupação de Ferrovia em Curitiba e em Almirante Tamandaré.

Em exercício rápido, imagina-se que Curitiba adote o despejo como medida de resolução da ocupação da faixa de domínio. O impacto sobre a cidade seria bastante considerável. $\mathrm{O}$ que se quer apresentar com isso é que a medida pode ser tomada e em alguns casos, a remoçáo pode ser necessária, porém, se realizada, deve ser aferida no conjunto das questóes atinentes aos impactos, riscos e mitigaçóes.

Em alguns casos, o risco pode ser muito significativo então a permanência pode não ser possível, mas, a saída deve ocorrer sem causar outros riscos, eventualmente até mais gravosos.

\section{RECOMENDAÇÓES TÉCNICAS}

Dada a vastidão da malha ferroviária, a necessidade de garantir segurança à população e a racionalização de recursos públicos, indica-se nesse estudo, Recomendaçóes Técnicas que não pretendem esgotar as possibilidades de respostas às questôes concernentes aos conflitos gerados pela inconveniência de diferentes e colidentes usos do mesmo território, mas, apontar açôes significativas de tratamento que vise minimizar os efeitos dos impactos e riscos próprios da atividade ferroviária.

A consideração sobre a localização inadequada da Ferrovia em área de urbanização consolidada, somada às condiçóes gerais territoriais, econômicas e metropolitana do Município de Almirante Tamandaré provoca a necessidade de se buscar medidas que não signifiquem novos riscos.

Nesse sentido, é de se mencionar que o tema em pauta trata de questão histórica, relacional, de demanda coletiva e de natureza complexa. Entende-se que os processos envolvidos devem ser tratados e discutidos na esfera coletiva uma vez que apresentam questóes que superam interesses meramente individuais.

A revisão da localização da Ferrovia permanece, devendo ser avaliada a necessidade de 
construção de anéis ou contornos ferroviários e ponderada a possibilidade de suspensão de processos em situaçóes que não apresentem riscos iminentes e que não possam ser imediatamente solucionados via conciliação.

São propostas as seguintes Recomendações Técnicas:

\section{(i) Indicação de Projeto para a Área de Influência da Ferrovia}

Apresentação de Estudo de Viabilidade Técnica, Econômica e Ambiental - EVETEA nos termos estabelecidos pelo DNIT, com a apresentação das áreas de influência direta e indireta.

Tendo em vista que o EVTEA visa resultados mais direcionados à Ferrovia e que o item socioeconômico não contempla questóes sociais e, do ponto de vista econômico trata de questôes específicas voltadas ao capital, outros estudos que considerem impactos sobre questôes em áreas urbanas consolidadas, compatibilidades e incompatibilidades, portanto, sobre as dinâmicas da cidade sobre a Ferrovia e da Ferrovia sobre a cidade devem ser considerados.

Nesse sentido, indica-se a realização ou apresentação, caso existam, dos Estudos de Impacto Ambiental e de Impacto de Vizinhança, conforme determinação da Lei Federal n. 10257/2001, Estatuto da Cidade.

Os estudos devem abordar os impactos positivos e negativos sobre o Município, especialmente, quando considerado que a malha ferroviária corta parte expressiva da malha urbana de Almirante Tamandaré, inclusive as áreas com mais recursos públicos investidos em infraestrutura, equipamentos e serviços.

Entende-se que a responsabilidade de apresentação e tais projetos é da empresa concessionária.

\section{(ii) Levantamento e Análise de Registros de Acidentes}

Tendo em vista que o debate versa sobre os riscos da convivência entre a Ferrovia e a dinâmica do espaço urbano é relevante para a análise de risco e mitigação de risco o Relatório Anual sobre Acidentes, constando dentre outros elementos:

a) o número de acidentes;

b) os pontos críticos e a gravidade de acidentes na área de influência da Ferrovia com imagens dos locais;

c) os tipos de acidentes;

d) os danos e suas respectivas características, considerados os diferentes sujeitos atingidos;

e) o acompanhamento realizado pela empresa concessionária;

f) as açôes de segurança e proteção;

g) as açôes mitigadoras. 


\section{(iii) Comparação com trechos anteriores e subsequentes}

A extensão da Ferrovia supera os limites do Município de Almirante Tamandaré, conectando-se com Municípios com população, densidade e pontos críticos de localização e de acidentes mais significativos.

A empresa concessionária deve demonstrar como tem atuado em Municípios que apresentam situaçóes mais críticas, em virtude de adensamento construtivo e populacional, número de cruzamentos, limites ao tráfego etc. tal como Curitiba e, em relação a outros que apresentam características semelhantes, de modo a estabelecer um roteiro de açóes adequadas e pertinentes às condiçóes gerais e específicas de segurança considerando, dentre outros aspectos, adensamento populacional, área de infraestrutura, equipamentos e serviços públicos, áreas de preservação de patrimônio natural ou construído.

\section{(iv) Plano de Remoçáo}

A medida apresentada pela empresa para a mitigação dos efeitos do impacto da Ferrovia sobre o Município indica à propositura de açóes judiciais de reintegraçáo de posse significativas do deslocamento de pessoas via despejo como meio de contenção do risco.

Tendo em vista que o despejo também apresenta risco, indica-se:

(i) levantamento e análise das espécies de risco e de sua gradação com Tabela de Classificação de Risco às Pessoas, tal como a que foi estabelecida para o risco de acidentes nas proximidades da Ferrovia;

(ii) realização de Plano de Relocação com indicação de localização próxima à área do despejo, e com indicação de medidas adequadas e seguras concernentes à remoção.

Uma vez que as atividades econômicas são beneficiárias dos resultados econômicos de suas atividades, as responsabilidades e respectivos ônus do exercício de suas respectivas açóes também são de sua responsabilidade.

Entende-se que o Plano deve ser realizado pela empresa concessionária, dado que o impacto e o risco são provocados pelo exercício da atividade econômica. Nesse sentido, devem ser realizados também os estudos e açóes mitigadoras já estabelecidos no item (i) das Recomendaçóes Técnicas.

\section{(v) Medidas de Segurança na Operação}

A empresa deve apresentar o Plano de Segurança de Operação, bem como realizar as medidas apresentadas no Plano observando dentre outros documentos, o Manual de Projeto de Interseçóes/DNIT, especialmente no que diz respeito aos cuidados decorrentes do uso da sinalização passiva e, também, da sinalização ativa, em virtude da quantidade de cruza- 
mentos e dos limites de mobilidade impostos pela Ferrovia a toda população.

Outras medidas de segurança também devem ser observadas, especialmente com vistas ao atendimento das diretrizes da Política Nacional de Mobilidade Urbana, Lei federal n. $12587 / 2012$.

O monitoramento das atividades, suas açóes e resultados devem ser devidamente publicizados.

Além das áreas de tráfego difuso, também aquelas consideradas como faixa de domínio, especialmente definidas na "Classificação de Risco às Pessoas" (ANTT) como de risco alto e muito alto devem ser identificadas com o objetivo de prevenir e inibir outros usos ou aproveitamentos conflitantes.

Considera-se importante também a propositura de projeto e implementação de contorno ferroviário, tal como já vem sendo objeto de debate ${ }^{2}$ nos Municípios integrantes da malha ferroviária metropolitana em que a rede atravessa as áreas urbanas, caso por exemplo de Curitiba e Almirante Tamandaré.

\section{(vi) Açóes Compartilhadas}

Há necessidade de diálogo entre os agentes mais diretamente implicados nos problemas e questóes decorrentes da Ferrovia.

Ações conjuntas podem minimizar os danos decorrentes dos impactos. Tais açóes podem ser planejadas e realizadas pelos agentes públicos e privados.

Entende-se que do ponto de vista das responsabilidades, esta é objetiva no que diz respeito à empresa operadora do serviço de transporte.

Por fim, entende-se que compreendida a complexidade da questão da disputa de usos em território de urbanização consolidada com presença de atividade de risco, as açóes devem contemplar as diferentes ordens de interesses que estão vigentes naquele mesmo espaço.

\footnotetext{
2 A proposta de contorno ferroviário já vem sendo proposta pelo Município de Curitiba, tal como ser observado na reportagem publicada na página da Prefeitura, em 31/05/2019 Disponível em: https://www. curitiba.pr.gov.br/noticias/curitiba-dara-suporte-a-secretaria-nacional-de-mobilidade/50744

A proposta não é atual e já contava, desde 2009 com plano de desativação do ramal ferroviário de Curitiba, mas, considerava também o Município de Almirante Tamandaré, como pode ser visto na reportagem do Jornal Gazeta do Povo em 05/08/2009. Dizia a reportagem ... "O plano consiste na desativação do ramal ferroviário ao longo de Curitiba, Almirante Tamandaré e Pinhais, numa extensão de 41,2 quilômetros. $\mathrm{O}$ projeto prevê a criação de dois traçados. $\mathrm{O}$ primeiro deles, a oeste, passaria pela Cidade Industrial de Curitiba (CIC) e contornaria o perímetro urbano de Almirante Tamandaré, paralelamente aos traçados dos Contornos Norte e Sul, chegando ao antigo ramal que liga Curitiba a Araucária. O outro traçado, a leste, seria implantado paralelamente ao Canal Extravasor, ao longo do Rio Iguaçu, ligando Piraquara a São José dos Pinhais. O desvio se conectaria ao ramal existente após a zona urbana de Pinhais, em direção a Piraquara, e integraria também o aeroporto Afonso Pena, em Pinhais, e os portos de Antonina e Paranaguá."

Disponível em: https:/www.gazetadopovo.com.br/vida-e-cidadania/contorno-ferroviario-aprovadobridtvl6r3zep7lw85ot3kp5a/
} 
Para tanto, a ponderação de direitos, a razoabilidade, a pertinência e a adequabilidade das ações são fundamentais na minimização dos riscos e dos impactos, especialmente sobre aqueles que se apresentam de modo mais frágil na teia de relaçóes necessariamente estabelecidas em virtude dos usos do território e que demandam direitos considerados fundamentais, essenciais à manutenção de vida.

O despejo também apresenta risco e as medidas concernentes à necessidade de relocação devem contemplar as condiçóes gerais territoriais e econômicas do próprio Município, a proximidade da área hoje ocupada, as condiçóes de habitabilidade e a segurança da posse na nova moradia.

Curitiba, 29 de janeiro de 2020.

\section{REFERÊNCIAS}

BRASIL. Agência Nacional de Transportes Terrestres. Relatório de Avaliação e Classificação de Risco de Invasóes na Faixa de Domínio no município de Almirante Tamandaré/PR: ação Civil Pública n. 5042024-28.2018.4.04.7000. 2019.

BRASIL. Agência Nacional de Transportes Terrestres. Relatório n. 102/2019/COFER/URRS. Inspeção Eventual Rumo Malha Sul S.A.. Trecho Sub-ramal de Rio Branco do Sul Segmento: km 13,00 ao KM 27,00 (Município de Almirante Tamandaré. 2019.

BRASIL. Agência Nacional de Transportes Terrestres. Anuário estatístico. Transporte de Carga Origem/Destino - 2006-2019. Disponível em: http://www.antt.gov.br/ferrovias/arquivos/ Anuario_Estatistico.html.

BRASIL. Código Civil, Lei Federal n. 10406/2002. Disponível em: http://www.planalto.gov.br/ ccivil_03/leis/2002/110406.htm.

BRASIL. Departamento Nacional de Infraestrutura de Transportes. DNIT Glossário de Termos Ferroviários. Disponível em: https://189.9.128.64/ferrovias/glossario-de-termos-ferroviarios/ glossario.pdf. p. 23.

BRASIL. Departamento Nacional de Infraestrutura de Transportes. DNIT Glossário de Termos Ferroviários. Manual de Projeto de Interseçôes/DNIT. Disponível em: http://www1.dnit.gov. br/ipr_new/..\%5Carquivos_internet\%5Cipr\%5Cipr_new\%5Cmanuais\%5CMANUAL_DE_ PROJETO_DE_INTERSECOES_Versao_Final.pdf.

GIESBRECHT, Ralph Mennucci. Estaçôes Ferroviárias do Brasil. Atualizado em 19/02/2018 Disponível em: http://www.estacoesferroviarias.com.br/pr-riobranco/almtamandare.htm.

Jornal Gazeta do Povo em 05/08/2009 https:/www.gazetadopovo.com.br/vida-e-cidadania/ contorno-ferroviario-aprovado-bridtvl6r3zep7lw85ot3kp5a/.

Município de Curitiba. página da Prefeitura, em 31/05/2019 Disponível em: https://www. curitiba.pr.gov.br/noticias/curitiba-dara-suporte-a-secretaria-nacional-de-mobilidade/ 50744 . 


\section{ANEXO \\ Levantamento das famílias realizado pela Secretaria Municipal de Habitaçáo}

USTAGEM MORADORES IARDIM DAS OUVEIRAS

\begin{tabular}{|c|c|c|c|c|c|}
\hline Mf & NOME DO RESPONSÁVEL FAMIUAR & \begin{tabular}{|l} 
ENOERECO \\
\end{tabular} & CRIANCA/ADOLESCENTE & IDOSO & $\begin{array}{l}\text { PESSOASCOM } \\
\text { DEFICIENCA }\end{array}$ \\
\hline & ADRIEU MARA RODPRGUES LSBOA & RUA VERON CA CASTRO PEREIRA, 169 & 2 & 0 & 0 \\
\hline 2 & ALLAN RAFAEL DE ABREU & RUA MARIIA ROSA MOREIRA DOS SANTOS, 53 & 1 & 0 & 0 \\
\hline & ANA PAULA RODRIGUES NOZARET & RUA MARIA ROSA MOREIRA DOS SANTOS, 130 & 1 & 0 & 0 \\
\hline 4. & ANA LUCA RIBESIRO DA SLVA & RUA DEZ, 15 & 1 & 0 & 0 \\
\hline 5. & ANGEUCA RODRIGUES OA SIIVA & RUA MAQAA ROSA MOREIRA DOS SANTOS, 361 & 4 & 0 & 0 \\
\hline 6 & ARAANE USBOA DOS SENTOS PODRIGUES & RUA MARAA ROSA MOREIRA DOS SENTOS, 310 & 4 & 0 & 0 \\
\hline 7 & ARELL PERELRA DA SIVA & RUA ANTONIO NOHMSON, 3011 & 1 & 0 & 0 \\
\hline 8. & ARINADOS ANNOS & RUA MARIA ROSA MOPEEIRA DOS SANTOS, 60 & 0 & 0 & 1 \\
\hline 9) & QELIDE USBOA ROORIGUES & RUA MARLA ROSA MOREIRA DOS SANTOS, 28 & 6 & 0 & 1 \\
\hline 10 & CLEIDE PINTO DE PAULA & RUA MARLA ROSA MOREIRA DOS SANTO5, 05 & 3 & 0 & 0 \\
\hline 11 . & DEEWR RODRIGUES & BUA MARIA ROSA MORERAR DOS SAETOS, 361 & 0 & 0 & 0 \\
\hline 12 & DEUSLENE DO ROCIO DASILVA & RUA WARLA ROSA MOEEERA DOS SANTOS, 55 & 0 & 0 & 1 \\
\hline 13. & DENSE PATRICLA EWANGEUSTA & RUA MARIA ROSA MORELRA DOS SANTOS, 310 F & 2 & 0 & 0 \\
\hline 14. & ELANE RIBERORO DA SUW & RUA MARLA AOSA MOAEIRA DOS SANTOS, 43 & 3 & 0 & 0 \\
\hline 15 & PRANOELE FARLA DE LARA & RUA UNIIO DA VITORIA, 55 & 2 & 0 & 0 \\
\hline 16. & GERIDOS SANTOS DE MENEZES & QUA MARIA ROSA MORERARA DOS SANTOS, 54 & 2 & 0 & 0 \\
\hline 17) & $10^{2}$ AO ALVES DOS SANTOS & RUA ANUETA SOUTO DE ANDRADE, 3075 & 1 & 0 & 0 \\
\hline 18) & KEVEUN DOS SANTOS RODEIGUES & RUA MARIA ROSA MORERIRA DOS SANTOS, 44 & 2 & 0 & 1 \\
\hline 19 & LOAENA DE OLVEIRA PEDOROSO & RUA ANTONIO IOHNSON, 28 & 1 & 0 & 0 \\
\hline 20 & MAYOO ANTONIO G1BIKOSSII & RUA MGRIA ROSA MOAEIRA DOS SANTOS, 43 & 2 & 0 & 0 \\
\hline 21 & MARIA ELZABETH MORERA & RUA MARAA ROSA MORERA DOS SANTOS, 56 & 0 & 0 & 0 \\
\hline 22 & MARIA JOSÉ RODRIGUES OOS SANTOS & RUA MARIA ROSA MORERARA DOS SANTOS, 19 & 2 & 0 & 0 \\
\hline 23 & MAPIANA RODRIGUES & RUA MARIA AOSA MOREIRA DOS SANTOS, 19 & 1 & 0 & 0 \\
\hline 24) & MAEU DE APARECIDA SANTOS & RUA IUUETA SOUTO DE ANDQADE, 950 & 1 & 0 & 0 \\
\hline 25 & \begin{tabular}{|l|} 
MARU RODARGUES \\
\end{tabular} & RUA MARIA ROSA MOREIRA DOS SANTOS, 120 & 2 & 0 & 0 \\
\hline 26. & NATAUNO HERECHUK & RUA MARIA ROSA MORELRA DOS SANTOS, 39 & 0 & 0 & 0 \\
\hline 27] & ODETE MATEUS & RUA MARIA ROSA MORERRA DOS SANTOS, 40 & 0 & 0 & 1 \\
\hline & ROSSON MISGA DE UMA & RUA MAPIA ROSA MOAEIRA DOS SANTOS, 55 & 0 & 0 & 0 \\
\hline
\end{tabular}




\begin{tabular}{|c|c|c|c|}
\hline $\begin{array}{l}\text { COMPOSIÇÁO } \\
\text { FAMILIAR }\end{array}$ & RENDA FAMILIAR & SITUAÇÃO DO IMÓVEL & $\begin{array}{c}\text { TEMPO NO } \\
\text { LOCAL }\end{array}$ \\
\hline 4 & $\mathrm{R} \$ 1.200,00$ & PRÓPRIO & 7 ANOS \\
\hline 2 & $\mathrm{R} \$ 1.200,00$ & CEDIDA & 5 ANOS \\
\hline 3 & $\mathrm{R} \$ 400,00$ & PRÓPRIA & 8 ANOS \\
\hline 3 & $\mathrm{R} \$ 200,00$ & ALUGADA & $\mathrm{x}$ \\
\hline 6 & $\mathrm{R} \$ 653,00$ & PRÓPRIA & $\mathrm{x}$ \\
\hline 6 & $\mathrm{R} \$ 1.575,00$ & PRÓPRIA & 22 ANOS \\
\hline 3 & $\mathrm{R} \$ 2.700,00$ & OCUPAÇÃO & $x$ \\
\hline 1 & $\mathrm{R} \$ 998,00$ & OCUPAÇÃO & 2 ANOS \\
\hline 11 & $\mathrm{R} \$ 998,00$ & PRÓPRIA & $x$ \\
\hline 5 & $\mathrm{R} \$ 1.200,00$ & OCUPAÇÄO & 30 ANOS \\
\hline 2 & $\mathrm{R} \$ 239,00$ & PRÓPRIA & 20 ANOS \\
\hline 4 & $\mathrm{R} \$ 1.998,00$ & PRÓPRIA & $\mathrm{x}$ \\
\hline 4 & $R \$ 2.400,00$ & OCUPAÇÃO & 10 ANOS \\
\hline 4 & $\mathrm{R} \$ 465,00$ & PRÓPRIA & $x$ \\
\hline 4 & $R \$ 1.169,00$ & OCUPAÇÃO & 6 ANOS \\
\hline 4 & $R \$ 1.500,00$ & OCUPAÇÃO & $x$ \\
\hline 3 & $R \$ 1.300,00$ & PRÓPRIA & $x$ \\
\hline 4 & $R \$ 1.200,00$ & PROPRIA & 17 ANOS \\
\hline 3 & $?$ & PRÓPRIA & 3 ANOS \\
\hline 6 & $\mathrm{R} \$ 1.400,00$ & OCUPAÇÃO & $x$ \\
\hline 2 & $\mathrm{R} \$ 800,00$ & PRÓPRIA & 13 ANOS \\
\hline 4 & $\mathrm{R} \$ 500,00$ & PRÓPRIA & $x$ \\
\hline 3 & $\mathrm{R} \$ 1.080,00$ & OCUPAÇÃO & 7 ANOS \\
\hline 3 & $\mathrm{R} \$ 1.200,00$ & OCUPAÇÃO & 13 ANOS \\
\hline 3 & $\mathrm{R} \$ 1.100,00$ & OCUPAÇÃO & $x$ \\
\hline 2 & $\mathrm{R} \$ 1.190,00$ & PRÓPRIA & 17 ANOS \\
\hline 3 & $R \$ 2.289,00$ & OCUPAÇÃO & 27 ANOS \\
\hline 2 & $\mathrm{R} \$ 2.300,00$ & PRÓPRIA & 8 ANOS \\
\hline
\end{tabular}

